\title{
Whale Washed Ashore at Ancona Linda Gregerson
}

\author{
anonymous engraving, 1601
}

Like a woman born inland

whose only allotment of sea is a notion

that starts in sand and never

comes home, this prodigy of flesh

and blood, "drawn faithfully from nature,"

will not find itself in nature, pure

and simple, again. The ear, for example. Where in mere ocean could a whale sprout ears? And where

but on this selvage between

one ravelling realm and the next could an engraver be so bold?

The whale is public spectacle. (Ignore for a moment the man with the ax.) Merchants on horseback and boys with their dogs

find no such cause for holiday

in many an entry of state.

See how the ladies, appearing to shrink,

are led from either end of the beach

for a view. The very waves exaggerate

their likeness to ribbons and lace, as if

to give the reticent more heart.

(And thus the ear. A touch of family for strangers to wear.) 
Thriving on one bountiful heap, the happy promoters of science and trade are all this while resourcefully

engaged; a group at the tail fin with measuring line, the one who has climbed to the shoulder applying his ax,

a motley remainder with barrels and carts. The boundaries of gain and exuberance aren't quite clear.

Dispensing refreshment? Harvesting oil? The row of tents suggests some length of stay. But lest the dense embellishment

impugn an engraver's strict regard for history and visible fact, witness the mirror he chose to consult:

a Whale Washed Ashore in Holland, some three years the elder event. Same horses, same dogs, and, but

for the mirror inversion, identical watchers and workers and sickle of shore. The duplicate ear. The same

slight backwash beneath an abandon of jaw. So faithfulness, and nature in a fashion too. The tide

comes bearing a gift sometimes and faithfully leaves us a margin to work and washes the whole of it clean. 